\title{
RESPONSABILIDADE TRIBUTÁRIA DO SÓCIO-GESTOR NA SOCIEDADE LIMITADA (ANÁLISE DO ART. 135, III, DO CÓDIGO TRIBUTÁRIO NACIONAL)
}

\author{
Renan Wanderley Santos Melo \\ Pós-graduado em Direito Tributário (FA7) e LLM em Direito \\ Corporativo (IBMEC). Advogado. \\ Artigo sob orientação do prof. Ms. Rui Farias (FA7). \\ renanwm@hotmail.com
}

Sumário: Introdução. 1. Responsabilidade tributária.

2. Responsabilidade de terceiros. Conclusão.

Resumo: O presente trabalho tem como objetivo a análise do art. 135, III, do Código Tributário Nacional. Para isso, é feita uma análise da responsabilidade no âmbito do Direito Tributário, enumerando os casos em que a responsabilidade recai em terceiros que não têm relação pessoal e direta com o fato gerador do tributo, ou seja, que não são contribuintes. Ao final, são analisadas decisões do Superior Tribunal de Justiça, mostrando a evolução da jurisprudência e traçando um panorama atual acerca da responsabilidade tributária do sócio-gestor da sociedade limitada.

Palavras-chave: Responsabilidade tributária. Sócio-gestor. Sociedade limitada. Atos irregulares.

\section{INTRODUÇÃO}

A ideia do presente trabalho surgiu da enorme quantidade de casos em que os sócios de sociedades com quotas de responsabilidade limitada são colocados no polo passivo de execuções fiscais, sendo que em regra não devem ser responsabilizados pelas dívidas das empresas.

Ocorre que há exceções a essa regra, e o Fisco usa justamente essas exceções para chegar aos sócios das empresas.

Isso acontece porque algumas normas do Código Tributário Nacional, apesar deste já possuir quase cinquenta anos, são motivo de várias discussões na doutrina e na jurisprudência, e uma delas é a norma contida no artigo 135, III.

A grande discussão se dá pelo fato da norma supracitada prever uma responsabilidade de diretores, gerentes e representantes de pessoas jurídicas de direito privado em determinadas situações e, em regra, na sociedade limitada, não há responsabilidade dos sócios pelas dívidas contraídas pela empresa.

Dessa forma, o que se questiona é: quando essa norma deve ser aplicada no caso das sociedades que preveem uma responsabilidade limitada dos seus sócios? Para essa pergunta existem várias respostas, encontradas em decisões dos Tribunais pátrios e na própria doutrina. Além 
disso, o Superior Tribunal de Justiça, órgão máximo no Brasil para tratar de questões federais, tem decisões diferentes acerca do assunto, o que acirra ainda mais a discussão sobre o tema.

O que se pretende fazer no presente artigo é analisar a norma contida no art. 135, III, do Código Tributário Nacional, para apresentar as hipóteses em que a responsabilidade pelo pagamento dos tributos devidos pela empresa atinja o seu sócio-gestor.

Com isso, serão analisados os requisitos para que se aplique a exceção contida na norma supracitada, os conceitos e as espécies de responsabilidade previstos no Código Tributário Nacional.

O estudo também se propõe a apresentar alguns julgados do Superior Tribunal de Justiça para que seja demonstrada a evolução da jurisprudência sobre o tema, fazendo-se uma análise crítica acerca da posição atual adotada pelo STJ.

Por fim, o que motivou a realização do presente estudo foi a busca de uma alternativa justa para o problema em questão, pois, apesar da jurisprudência ter evoluído muito no que concerne à interpretação do dispositivo em questão, ainda há muito o que evoluir para que os direitos do contribuinte não sejam desrespeitados pelo Fisco, já que este tem se aproveitado desta exceção prevista no Código Tributário Nacional para responsabilizar o sócio indistintamente, sem obedecer às normas da legislação tributária e societária.

\section{Responsabilidade Tributária}

\subsection{Conceito}

No âmbito do direito tributário, a palavra responsabilidade assume dois significados, um lato sensu e um stricto sensu.

De acordo com Machado (2010, p. 158):

Em sentido amplo, é a submissão de determinada pessoa, contribuinte ou não, ao direito do fisco de exigir a prestação da obrigação tributária. Essa responsabilidade vincula qualquer dos sujeitos passivos da relação obrigacional tributária.

Em sentido estrito, é a submissão, em virtude de disposição legal expressa, de determinada pessoa que não é contribuinte, mas está vinculada ao fato gerador da obrigação tributária, ao direito do fisco de exigir a prestação respectiva.

O presente estudo é voltado especialmente para a responsabilidade tributária em sentido estrito, que está prevista no art. 121, II do Código Tributário Nacional.

Sabe-se que existem dois tipos de sujeito passivo da obrigação tributária, a saber, o contribuinte e o responsável. O primeiro é aquele que tem uma relação direta e pessoal com o fato gerador e o segundo, aquele que tem a obrigação de pagar o tributo em virtude de expressa previsão legal.

Porém, a lei não pode determinar que qualquer pessoa seja responsável pelo pagamento de um tributo - a pessoa deve ter um vínculo com o fato gerador da obrigação tributária. $\mathrm{O}$ art. 128 do CTN diz:

Art. 128. Sem prejuízo do disposto neste capítulo, a lei pode atribuir de modo expresso a responsabilidade pelo crédito tributário a terceira pessoa, vinculada ao fato gerador da respectiva obrigação, excluindo a responsabilidade do contribuinte ou atribuindo-se a este em caráter supletivo do cumprimento total ou parcial da referida obrigação.

Importante salientar que não é qualquer espécie de vínculo com o fato gerador da obrigação tributária que pode gerar a responsabilidade de terceira pessoa. Segundo Amaro (2011, p. 338): 


\begin{abstract}
Em suma, o ônus do tributo não pode ser deslocado arbitrariamente pela lei a qualquer pessoa (como responsável por substituição, por solidariedade ou por subsidiariedade), ainda que vinculada ao fato gerador, se essa pessoa não puder agir no sentido de evitar esse ônus nem tiver como diligenciar no sentido de que o tributo seja recolhido à conta do indivíduo que, dado o fato gerador, seria elegível como contribuinte.
\end{abstract}

Pois bem. Tem-se, portanto, que responsabilidade tributária é a sujeição de alguém ao direito do fisco de exigir o pagamento da obrigação tributária, podendo o sujeito passivo desta obrigação ser o contribuinte, que é aquele que tem uma relação pessoal e direta com o fato gerador, ou o responsável, que é aquele que não tem relação direta e pessoal com o fato gerador, mas possui um vínculo com este.

\title{
1.2 Espécies
}

O Código Tributário Nacional prevê três tipos de responsabilidade tributária. São elas: responsabilidade dos sucessores; responsabilidade de terceiros; responsabilidade por infrações.

A responsabilidade dos sucessores está prevista nos artigos 129 a 133 do CTN. A sucessão modifica o sujeito passivo da obrigação tributária. Dessa forma, o sucessor passa a ocupar o lugar do antigo devedor, na situação em que a obrigação se encontrava no momento do acontecimento que fundamentou a sucessão.

No que concerne a tributos referentes a bens imóveis, a regra prevista no art. 130 do CTN diz que os créditos tributários relativos à propriedade, domínio útil ou posse desses bens sub-rogam-se na pessoa do adquirente, a não ser que conste do título a prova de sua quitação. O parágrafo único do artigo supracitado também excepciona os casos de arrematação em hasta pública - nestes casos, o arrematante não fica responsável pelos tributos.

No art. 131 do CTN estão previstas outras modalidades de responsabilidade por sucessão. De acordo com a referida norma, são pessoalmente responsáveis pelo pagamento do tributo: o adquirente ou remitente, pelos bens adquiridos ou remidos, sejam eles móveis ou imóveis; o sucessor e o cônjuge meeiro, pelos tributos devidos pelo de cujus até a data da partilha ou adjudicação, sendo que esta responsabilidade é limitada até o montante do quinhão, legado ou meação; o espólio, pelos tributos devidos pelo de cujus até a data da abertura da sucessão.

A regra contida no art. 132 do CTN refere-se às empresas resultantes de fusão, transformação ou incorporação. Estas são responsáveis pelos tributos devidos pelas empresas fusionadas, transformadas ou incorporadas até a data do ato. Importante observar que a operação denominada "cisão" também deve ser incluída nesta regra, tendo em vista que passou a ser prevista no ordenamento com o advento da Lei 6.404/76.

De acordo com o parágrafo único do art. 132 do $\mathrm{CTN}$, a mesma regra supramencionada se aplica nos casos em que, após a extinção da pessoa jurídica, um sócio remanescente ou seu espólio continue a mesma atividade sob a mesma ou outra razão social ou mesmo sob firma individual. Essa regra tem o objetivo de evitar alguns tipos de fraude.

A última regra referente à responsabilidade por sucessão está contida no art. 133 do CTN. Segundo essa regra, a pessoa que adquirir fundo de comércio ou estabelecimento e continuar a exploração da atividade responde pelos tributos do estabelecimento adquirido. Essa responsabilidade pode ser: integral, quando o alienante cessa a exploração da atividade; subsidiária, quando o alienante continua na exploração da atividade ou inicie dentro de seis meses, contados da alienação, a mesma ou nova atividade.

$\mathrm{O} \S 1^{\circ}$ do art. 133 excepciona essa regra nos casos de alienação judicial em processo de falência ou em processo de recuperação judicial. 
Com o objetivo, mais uma vez, de evitar fraudes, foi criada a regra do $\S 2^{\circ}$ do artigo em questão, em que se faz uma "exceção da exceção" do $\S 1^{\circ}$. Segundo a regra contida no dispositivo legal, não se aplica a exceção do $\S 1^{\circ}$ nos casos em que o comprador for sócio da empresa falida ou em recuperação judicial, ou for agente ou parente do falido ou devedor em recuperação judicial.

Feita uma breve exposição acerca da responsabilidade dos sucessores, passa-se à análise da responsabilidade por infrações, posto que a chamada responsabilidade de terceiros será analisada em capítulo próprio.

A responsabilidade por infrações independe da intenção do agente ou do responsável. Independe também da natureza, efetividade e extensão dos efeitos da ação ou omissão (art. 136 do CTN).

De acordo com Machado (2010, p. 171), esse artigo não prevê uma responsabilidade objetiva, mas sim por culpa presumida. A diferença é que na responsabilidade objetiva não se questiona a culpa do agente, ao contrário da responsabilidade por culpa presumida, em que não há necessidade de demonstrar a culpa, mas caso o interessado prove que agiu sem a intenção de infringir a lei, que na verdade tentou cumpri-la, mas não foi possível por motivos além da sua vontade, ele afasta a sua responsabilidade.

Machado Segundo (2009, p. 264) afirma que se deve examinar o artigo em conjunto com o art. 137, que consagra a responsabilidade subjetiva e, por isso, concorda que não se pode dizer que a responsabilidade prevista no artigo em questão é objetiva.

Porém, existem autores como Ribeiro Neto (2011, p. 197) que acreditam que a responsabilidade prevista no art. 136 é objetiva, pois não depende da vontade do agente ou responsável. Com o devido respeito, o presente estudo irá se pautar na primeira posição.

$\mathrm{O}$ art. 137 prevê uma responsabilidade pessoal do agente:

Art. 137. A responsabilidade é pessoal ao agente:

I - quanto às infrações conceituadas por lei como crimes ou contravenções, salvo quando praticadas no exercício regular de administração, mandato, função, cargo ou emprego, ou no cumprimento de ordem expressa emitida por quem de direito;

II - quanto às infrações em cuja definição o dolo específico do agente seja elementar; III - quanto às infrações que decorram direta e exclusivamente de dolo específico:

a) das pessoas referidas no artigo 134, contra aquelas por quem respondem;

b) dos mandatários, prepostos ou empregados, contra seus mandantes, preponentes ou empregadores;

c) dos diretores, gerentes ou representantes de pessoas jurídicas de direito privado, contra estas.

Amaro (2011, p. 473) faz uma comparação entre os artigos 136 e 137 do CTN:

Vimos, no art. 136, que a responsabilidade por infrações independe da intenção "do agente ou do responsável", e concluímos que o Código Tributário Nacional quis abranger, com essa locução, as figuras do agente ou executor material do ato (quando se trate do próprio interessado em dada situação material à qual o ato se conecte), e o terceiro, em nome e por conta de quem o agente tenha praticado o ato. Esse terceiro é que é o "responsável", na citada alternativa: "agente ou responsável".

Agora, no art. 137, o Código arrola situações em que a responsabilidade por infrações é pessoal do agente, não, obviamente, em situação na qual ele atue em seu nome e por sua conta, hipótese em que não haveria dúvida, mas em casos nos quais, agindo embora em nome e por conta de terceiro, a responsabilidade é imputada ao próprio agente ou executor material. 
Desta forma, nas hipóteses definidas no art. 137, responsabiliza-se pessoalmente o autor da ação ou omissão que atue em nome de outrem.

Por fim, o Código Tributário Nacional prevê em seu art. 138 a denominada “denúncia espontânea", estatuto criado para estimular o cumprimento das obrigações tributárias por parte dos responsáveis. Assim, quando ocorre a denúncia espontânea, desde que antes de procedimento administrativo ou medida de fiscalização referente à infração, a responsabilidade é excluída.

\title{
2 Responsabiliddade de TerCeIRos
}

A responsabilidade de terceiros está prevista nos artigos 134 e 135 do CTN, sendo que o primeiro artigo trata da responsabilidade por atos regulares e o segundo trata de responsabilidade por atos irregulares.

\subsection{Responsabilidade de terceiros por atos regulares $\mathrm{x}$ irregulares}

$\mathrm{O}$ art. 134 prevê uma responsabilidade subsidiária, pois afirma que a responsabilidade surge com a impossibilidade de cumprimento da obrigação pelo contribuinte:

\begin{abstract}
Art. 134. Nos casos de impossibilidade de exigência do cumprimento da obrigação principal pelo contribuinte, respondem solidariamente com este nos atos em que intervierem ou pelas omissões de que forem responsáveis:

I - os pais, pelos tributos devidos por seus filhos menores;

II - os tutores e curadores, pelos tributos devidos por seus tutelados ou curatelados;

III - os administradores de bens de terceiros, pelos tributos devidos por estes;

IV - o inventariante, pelos tributos devidos pelo espólio;

V - o síndico e o comissário, pelos tributos devidos pela massa falida ou pelo concordatário;

VI - os tabeliães, escrivães e demais serventuários de ofício, pelos tributos devidos sobre os atos praticados por eles, ou perante eles, em razão do seu ofício;

VII - os sócios, no caso de liquidação de sociedade de pessoas.

Parágrafo único. O disposto neste artigo só se aplica, em matéria de penalidades, às de caráter moratório.
\end{abstract}

Quando o artigo fala em responsabilidade solidária, o que se quer dizer é que a responsabilidade é solidária entre os responsáveis, e não entre estes e o contribuinte.

Lido o artigo, ficam claros os dois requisitos para que surja a responsabilidade subsidiária de terceiro prevista no art. 134 do CTN: a impossibilidade de cumprimento da obrigação pelo contribuinte e a participação do terceiro no ato, seja essa participação de forma comissiva ou omissiva. Dessa forma, não é qualquer vínculo que irá gerar essa responsabilidade. Ensina Amaro (2011, p. 352 e 353):

Observe-se que não basta o mero vínculo decorrente da relação de tutela, inventariança etc., para que se dê a eleição do terceiro como responsável; requer-se que ele tenha praticado algum ato (omissivo ou comissivo), pois sua responsabilidade se conecta com os atos em que tenha intervindo ou com as omissões pelas quais for responsável.

O parágrafo único do art. 134 ainda deixa claro que só se aplicam a esses responsáveis as penalidades de caráter moratório.

No que concerne à responsabilidade de sócios, tem-se que estes podem responder pelos débitos tributários de suas empresas, no caso de liquidação destas. Mas não é qualquer tributo que será responsabilidade do sócio, devendo-se observar os requisitos do art. 134. 
Diferente do artigo supracitado, o art. 135 do CTN prevê uma responsabilidade pessoal pelo pagamento do tributo:

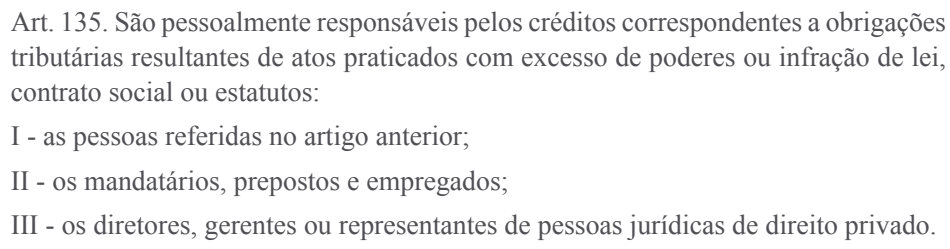

Art. 135. São pessoalmente responsáveis pelos créditos correspondentes a obrigações tributárias resultantes de atos praticados com excesso de poderes ou infração de lei, contrato social ou estatutos:

I - as pessoas referidas no artigo anterior;

II - os mandatários, prepostos e empregados;

III - os diretores, gerentes ou representantes de pessoas jurídicas de direito privado.

Nesse artigo, ao contrário do anterior, a responsabilidade não é subsidiária, é pessoal. Outra diferença é que o art. 135 prevê a prática de ato irregular.

Assim, verifica-se uma possibilidade de responsabilidade do sócio-gestor da sociedade limitada, mas é importante perceber que o inciso III do artigo não fala em sócio, fala em diretor, gerente ou representante. Portanto, o sócio, neste caso, só poderá responder se for sócio-gestor. Se for meramente sócio-quotista, não está incluído nessa possibilidade.

Com o estudo dos artigos que tratam da responsabilidade de terceiros, percebe-se que o art. 134 prevê uma responsabilidade por atos regulares e o art. 135 prevê uma responsabilidade por atos irregulares.

O art. 134 não deve ser aplicado para responsabilizar sócios ou administradores de sociedades de capital, visto que é bem claro ao mencionar "sociedade de pessoas". Só vai haver responsabilidade de administradores ou sócios-administradores quando houver a prática de ato irregular, ou seja, com base no art. 135.

Para a aplicação da responsabilidade de terceiro por ato irregular é necessário um requisito elementar: prática de algum ato para o qual o terceiro não tinha poderes ou de ato que infringiu a lei, estatuto ou contrato social.

\subsection{Extensão da responsabilidade dos administradores/gestores em decorrência da atuação irregular}

Parte da doutrina acredita que, ao mencionar o termo "pessoalmente responsáveis", o CTN retira o contribuinte do polo passivo e coloca o terceiro no seu lugar. Segundo Amaro (2011, p. 353 e 354$)$ :

\footnotetext{
Em confronto com o artigo anterior, verifica-se que esse dispositivo exclui do polo passivo da obrigação a figura do contribuinte (que, em princípio, seria a pessoa em cujo nome e por cuja conta agiria o terceiro), ao mandar que o executor do ato responda pessoalmente. A responsabilidade pessoal deve ter aí o sentido (que já se adivinhava no art. 131) de que ela não é compartilhada com o devedor "original" ou "natural".

Não se trata, portanto, de responsabilidade subsidiária do terceiro, nem de responsabilidade solidária. Somente o terceiro responde, "pessoalmente".
}

Essa posição é seguida por alguns tributaristas brasileiros, como Marques (2004, p. 67), que em artigo escrito afirma que a responsabilidade no caso não é solidária. Souza e Funaro (2007, p. 54) também acreditam que a responsabilidade prevista na norma em questão exclui do polo passivo o contribuinte.

Por outro lado, outra parcela importante da doutrina acredita que o art. 135 prevê uma responsabilidade solidária entre o terceiro e o contribuinte. Segundo Machado (2010, p. 167):

Note-se que as pessoas mencionadas no art. 134, se agirem com excesso de mandato, infração à lei ou contrato, assumem plena responsabilidade pelos créditos 
tributários respectivos. Deixam de responder apenas na impossibilidade de exigência do cumprimento da obrigação principal pelo contribuinte, e passam à posição de responsáveis solidários.

Ribeiro Neto (2011, p. 197) é também adepto dessa corrente, assim como muitos outros tributaristas e o autor do presente trabalho, com todo respeito aos autores defensores da primeira corrente.

Visto essa divergência, passa-se agora à análise da responsabilidade dos sócios-administradores das empresas decorrente de atuação irregular, objeto do inciso III do art. 135 e tema central do presente estudo.

Como se sabe, na sociedade limitada a responsabilidade dos sócios é limitada às suas quotas. Essa é a grande vantagem de se constituir esse tipo de sociedade.

Já foram vistas as situações em que a responsabilidade pode recair nos sócios desses tipos de sociedade. Para isso é necessário, primeiramente, que o sócio seja o gestor da sociedade. Assim, a partir de agora, quando se falar em sócio, se estará referindo ao sócio-gestor, pois quanto ao sócio meramente quotista, não há discussão, este não poderá ser responsabilizado pelas dívidas da empresa.

Não basta que o sócio seja o gestor, deve ele agir com excesso de mandato, infração à lei, estatuto ou contrato social da empresa, e o crédito tributário deve ser decorrente dessa ação ou omissão.

Portanto, deve-se analisar tudo isso antes de colocar o sócio como sujeito passivo da obrigação, primeiro ver se ele é o gestor da empresa, pois é a condição de gestor que responsabiliza, e não a de sócio, e, depois, ver se o crédito resulta de ato irregular praticado por ele.

De todos os dispositivos analisados, tem-se que a regra é a não responsabilização dos sócios pelo pagamento de tributos devidos pelas sociedades empresárias, porém, existe a exceção prevista no art. 135, III do Código Tributário Nacional.

Dessa forma, são necessárias as condições acima estudadas para direcionar a responsabilidade tributária para os sócios, e, para colocar os nomes destes na Certidão de Dívida Ativa, é necessário antes apurar se é caso de aplicação dessa responsabilidade através de procedimento administrativo. Ensina Machado Segundo (2010, p. 240):

\footnotetext{
Em nosso entendimento, para atribuir responsabilidade tributária às pessoas referidas no artigo 135 do CTN é indispensável a instauração de processo administrativo específico. Trata-se, aliás, de um privilégio do Fisco, vez que os demais credores se têm de valer de ação judicial. O puro e simples "redirecionamento" da execução fiscal para as pessoas referidas no art. 135, III, do CTN, em regra, só é possível nas hipóteses em que, quando da busca de bens para penhora, constata-se o irregular e completo desaparecimento da pessoa jurídica. Essa hipótese, aliás, autoriza o redirecionamento de qualquer execução, e não apenas da promovida pela Fazenda Pública.
}

A Fazenda Pública não pode colocar o nome do sócio na CDA indistintamente, porém, o Fisco enxerga o dispositivo em tela como uma solução para que os seus créditos sejam adimplidos. Por isso, costuma fazer uma interpretação demasiadamente extensiva da norma e acaba por abarcar todos os casos em que a empresa figura no polo passivo.

A tese fazendária normalmente afirma que não é necessária a comprovação do ato irregular. Costuma colocar qualquer sócio, independentemente de ser gestor ou não, no polo passivo e afirma também que o simples inadimplemento da pessoa jurídica já é infração à lei capaz de gerar a responsabilidade do sócio, argumento este que, como será visto, já foi aceito pelo STJ, porém, foi superado. 
São justamente essas teses fazendárias que fazem com que o assunto se torne polêmico e motivo de tanta discussão no Superior Tribunal de Justiça, tendo este Tribunal evoluído bastante na interpretação da norma em questão, como será visto no tópico seguinte, em que serão analisadas algumas decisões do STJ, que são de grande importância para fins práticos por este ser o tribunal que detém a última palavra no que concerne à interpretação da legislação federal.

\title{
2.3 Casuística e exame da jurisprudência do STJ
}

Ao longo dos anos, a jurisprudência do Superior Tribunal de Justiça vem evoluindo ao aplicar o art. 135, III do CTN. A tese defendida pelo STJ já foi a de que basta que não haja o recolhimento do tributo devido pela sociedade para que se responsabilize o sócio-gerente. In verbis:

\begin{abstract}
RIBUTÁRIO - RESPONSABILIDADE PESSOAL DO SÓCIO-GERENTE AUSÊNCIA DE RECOLHIMENTO DE TRIBUTOS DEVIDOS PELA SOCIEDADE. Os sócios-gerentes são responsáveis pela dívida tributária resultante de atos praticados com infração à lei e quem deixa de recolher tributos devidos pela sociedade comete infração à lei. Recurso improvido. (Ac. Un. da 1ª T. do STJ - Resp 203.878/RJ - Rel Min. Garcia Vieira - DJU I de 21.6.1999, p. 96).
\end{abstract}

Essa tese está superada, pois caso ainda fosse adotada, a exceção prevista no dispositivo em estudo viraria a regra. O que passou a prevalecer foi que o simples inadimplemento não gera a responsabilidade do sócio-gerente. Esse entendimento foi, inclusive, sumulado Súmula 430 do STJ: "O inadimplemento da obrigação tributária pela sociedade não gera, por si só, a responsabilidade solidária do sócio-gerente".

Dessa forma, hoje, é uníssono o entendimento do Superior Tribunal de Justiça no sentido de que é indispensável a comprovação de culpa no ato irregular, que vai contra lei, estatuto ou contrato social da empresa, para que seja configurada a responsabilidade do sócio-gestor.

Apesar da evolução da jurisprudência, a impressão que se tem é que esta ainda deve evoluir, pois ainda encontra, data venia, algumas imprecisões e omissões.

O Superior Tribunal de Justiça, apesar de já ter pacificado o entendimento de que deve ser comprovada a atividade irregular do sócio-gestor, não definiu com clareza quando esta hipótese resta configurada.

Em alguns julgados, o STJ já se posicionou no sentido de que caso o sócio-gestor seja o responsável pelo recolhimento do bônus lucrativo da sociedade, mas não verifica o adimplemento dos tributos, comete ato ilícito e faz surgir sua responsabilidade (STJ - ${ }^{\text {a }}$ Turma $-\mathrm{AgRg}$ nos Edcl no Resp 510.590 - Rel. Min. Luiz Fux - DJ de 01/03/2004).

Essa presunção, por óbvio, é relativa, podendo, inclusive, ser comprovado o contrário em sede de exceção de pré-executividade.

Outra presunção criada pelo STJ é a da Súmula 435. Segundo esta, quando uma empresa muda seu domicílio sem informar para a autoridade competente, presume-se dissolvida irregularmente, recaindo a responsabilidade para o sócio.

Como dito, essa presunção também é relativa, pois comporta prova em contrário.

Por fim, tem-se que hoje há uma discussão acerca do momento da inclusão do nome do sócio-gestor na CDA. Não restam dúvidas de que para executar o sócio-gestor de uma pessoa jurídica é necessário que o nome deste conste no título executivo. A partir daí já se conclui que, em tese, seria impossível executar esse sócio se apenas o nome da empresa constar na CDA.

Porém, o STJ tem admitido a inclusão posterior do nome do sócio na CDA, desde que a Fazenda Pública prove, nos autos da execução, os motivos do redirecionamento: 
PROCESSUAL CIVIL. RECURSO ESPECIAL. TRIBUTÁRIO. EXECUÇÃO FISCAL. RESPONSABILIDADE DO SÓCIO-GERENTE. EXECUÇÃO QUE CONSTA NO POLO PASSIVO A SOCIEDADE DEVEDORA E OS SÓCIOS. PENHORA. SISTEMA BACEN-JUD. LEI N ${ }^{\circ} 11.382 / 2006$. ARTS. 655, I E 655-A, DO CPC. TEMPUS REGIT ACTUM. RECURSO ESPECIAL REPRESENTATIVO DE CONTROVÉRSIA N ${ }^{\circ}$ 1184765/PA. NOMEAÇÃO DE DEPOSITÁRIO. RECUSA AO ENCARGO. POSSIBILIDADE. SÚMULA 319 DO STJ. 1. O redirecionamento da execução fiscal, e seus consectários legais, para o sócio-gerente da empresa, somente é cabível quando reste demonstrado que este agiu com excesso de poderes, infração à lei ou contra o estatuto, ou na hipótese de dissolução irregular da empresa, não se incluindo o simples inadimplemento de obrigações tributárias.

$[\ldots]$

3. A jurisprudência da Primeira Seção desta Corte Superior ao concluir o julgamento do ERESP n ${ }^{\circ} 702.232 / \mathrm{RS}$, da relatoria do e. Ministro Castro Meira, publicado no DJ de 26.09.2005, assentou que: a) se a execução fiscal foi ajuizada somente contra a pessoa jurídica e, após o ajuizamento, foi requerido o seu redirecionamento contra o sócio-gerente, incumbe ao Fisco a prova da ocorrência de alguns dos requisitos do art. 135, do CTN: a) quando reste demonstrado que este agiu com excesso de poderes, infração à lei ou contra o estatuto, ou na hipótese de dissolução irregular da empresa; b) constando o nome do sócio-gerente como corresponsável tributário na CDA cabe a ele o ônus de provar a ausência dos requisitos do art. 135 do CTN, independentemente se a ação executiva foi proposta contra a pessoa jurídica e contra o sócio ou somente contra a empresa, tendo em vista que a CDA goza de presunção relativa de liquidez e certeza, nos termos do art. 204 do CTN c/c o art. $3^{\circ}$ da Lei $\mathrm{n}^{\circ} 6.830 / 80.4$. Os fundamentos de referido aresto restaram sintetizados na seguinte ementa: "TRIBUTÁRIO. EMBARGOS DE DIVERGÊNCIA. ART. 135 DO CTN. RESPONSABILIDADE DO SÓCIO-GERENTE. EXECUÇÃO FUNDADA EM CDA QUE INDICA O NOME DO SÓCIO. REDIRECIONAMENTO. DISTINÇÃO. 1. Iniciada a execução contra a pessoa jurídica e, posteriormente, redirecionada contra o sócio-gerente, que não constava da CDA, cabe ao Fisco demonstrar a presença de um dos requisitos do art. 135 do CTN. Se a Fazenda Pública, ao propor a ação, não visualizava qualquer fato capaz de estender a responsabilidade ao sócio-gerente e, posteriormente, pretende voltar-se também contra o seu patrimônio, deverá demonstrar infração à lei, ao contrato social ou aos estatutos ou, ainda, dissolução irregular da sociedade. 2. Se a execução foi proposta contra a pessoa jurídica e contra o sócio-gerente, a este compete o ônus da prova, já que a CDA goza de presunção relativa de liquidez e certeza, nos termos do art. 204 do CTN c/c o art. $3^{\circ}$ da Lei $n^{\circ} 6.830 / 80$. 3. Caso a execução tenha sido proposta somente contra a pessoa jurídica e havendo indicação do nome do sócio-gerente na CDA como corresponsável tributário, não se trata de típico redirecionamento. Neste caso, o ônus da prova compete igualmente ao sócio, tendo em vista a presunção relativa de liquidez e certeza que milita em favor da Certidão de Dívida Ativa. 4. Na hipótese, a execução foi proposta com base em CDA da qual constava o nome do sócio-gerente como corresponsável tributário, do que se conclui caber a ele o ônus de provar a ausência dos requisitos do art. 135 do CTN. 5. Embargos de divergência providos". (...) (STJ - 1ª Turma - AgRg no REsp 1196537/MG - Rel. Min. Luiz Fux - DJ de 22/02/2011)

Importante salientar que esse redirecionamento deve ter um prazo prescricional, pois, caso não houvesse, tornaria a dívida imprescritível. O prazo é de cinco anos, contados do despacho que determinou a citação da pessoa jurídica na execução fiscal.

O que mais gera discussão, porém, é o posicionamento do STJ acerca dos casos em que o nome do sócio consta na CDA desde o início. Segundo o tribunal, como visto, devido à presunção de certeza e liquidez da $\mathrm{CDA}$, quando nesta já consta o nome do sócio, é este quem deve provar a não ocorrência dos requisitos do art. 135, III. 
Esse posicionamento jurisprudencial faz com que a Fazenda Pública coloque o nomes dos sócios nas CDAs indistintamente, pois alega que o sócio é quem tem que provar que não é responsável.

Esse entendimento, data máxima venia, não é o mais acertado. Se o Fisco coloca o nome do sócio na CDA, o Fisco que tem que provar a ocorrência de fato que se enquadre na hipótese do art. 135, III. A prova cabe a quem faz a alegação, devendo haver, antes da inclusão do nome do sócio na CDA, um procedimento administrativo por parte do Fisco que demonstre essa responsabilidade. Mas não é isso que vem acontecendo.

O correto seria dar oportunidade ao sócio em questão para que este se defendesse em processo administrativo, para que fosse consagrado o princípio do contraditório. $\mathrm{O}$ fato de o sócio ter o ônus de provar na execução fiscal a não ocorrência de um fato torna o processo extremamente desigual.

Dessa forma, tem-se que o atual posicionamento do Superior Tribunal de Justiça é o de que: não basta o mero inadimplemento do tributo para a configuração da responsabilidade do sócio-gestor da sociedade limitada, porém, existem algumas formas de se presumir essa responsabilidade; no caso de redirecionamento da execução fiscal para o sócio da empresa, a Fazenda tem que juntar prova de que é caso de responsabilização daquele, e tem um prazo de cinco anos para fazer esse redirecionamento; caso na CDA já conste o nome do sócio, a este cabe provar que não é caso de aplicação do art. 135, III do Código Tributário Nacional.

\section{Conclusão}

Feita a análise doutrinária e jurisprudencial acerca da aplicação do art. 135, III do Código Tributário Nacional, verifica-se que esse dispositivo é uma exceção que não pode ser aplicado indistintamente, só devendo ser aplicado quando o sócio-gestor agir com excesso de mandato, ou praticar ato em desconformidade com a lei, o estatuto ou o contrato social da empresa, ou ainda no caso de dissolução irregular da empresa.

Conclui-se também que a jurisprudência do Superior Tribunal de Justiça em muito já evoluiu no que concerne à aplicação dessa norma, porém, ainda vem admitindo a inclusão do nome do sócio na CDA sem que o Fisco comprove que é caso de incidência do dispositivo em questão, transferindo o ônus da prova para o sócio da empresa.

Dessa forma, apesar da evolução, o que se vê é que a jurisprudência precisa evoluir ainda mais para que a exceção não se torne a regra e o contribuinte tenha seus direitos resguardados diante do enorme poder do Fisco.

\section{REFERÊNCIAS}

AMARO, Luciano. Direito Tributário Brasileiro. 17. ed. São Paulo: Saraiva, 2011.

BRASIL. Código Tributário Nacional. 17. ed. São Paulo: Saraiva, 2011.

. Superior Tribunal de Justiça. Ac. Un. da $1^{\text {a }}$ T. do STJ - Resp 203.878/RJ - Rel Min. Garcia Vieira - DJU I de 21.6.1999, p. 96. Disponível em: $<$ http://www.stj.jus.br/SCON/jurisprudencia/toc.jsp?tipo visualizacao $=$ RESUMO\&processo $=203878 \& b=A C O R>$. Acesso em: $15 / 05 / 2011$.

. Superior Tribunal de Justiça. AgRg no REsp 1196537 MG -Rel. Min. Luis Fux - DJ de 22/02/2011. Disponível em: $<$ http://www.stj.jus.br/SCON/jurisprudencia/toc.jsp?tipo visual

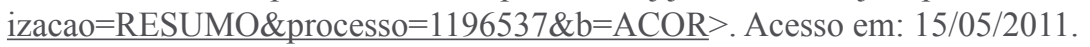


MACHADO, Hugo de Brito. Curso de Direito Tributário. 31. ed. São Paulo: Malheiros, 2010.

MACHADO SEGUNDO, Hugo de Brito. Código Tributário Nacional: anotações à Constituição, ao Código Tributário Nacional e às leis complementares 87/1996 e 116/2003. 2. ed. São Paulo: Atlas, 2009.

Processo Tributário. 5. ed. São Paulo: Atlas, 2010.

MARQUES, Leonardo Nunes. A responsabilidade dos membros da sociedade limitada pelas obrigações tributárias e o novo Código Civil. Revista dialética de direito tributário. № 111. São Paulo: Dialética, 2004, p. 60.

RIBEIRO NETO, José. Direito Tributário e legislação tributária do Estado do Ceará: comentários, doutrina e jurisprudência. 4. ed. Fortaleza: Fortes, 2011.

SOUZA, Hamilton Dias de. FUNARO, Hugo. A desconsideração da personalidade jurídica e a responsabilidade tributária dos sócios e administradores. Revista dialética de direito tributário. No 137. São Paulo: Dialética, 2007, p. 38.

\section{TAX LIABILITY IN LIMITED PARTNERSHIP}

Abstract: This study aims the analysis of article 135, III, of Brazil's National Tax Code, considering the liability under the tax law, enumerating the cases where the responsibility lies on third parties that do not have direct personal relationship with the triggering event of the tribute. Decisions of the Superior Court of Justice are analysed, showing the evolution of case law and drawing a current picture about tax liability of the partner manager of a limited partnership.

Keywords: Tax liability. Partner manager. Limited Partnership. Irregular procedure.

Data de recebimento: dez/2011 - Data de aprovação: nov/2012 